\title{
РЕЗУЛЬТАТЫ КЛИНИЧЕСКОЙ ОЦЕНКИ КАЧЕСТВА ВРЕМЕННЫХ ОРТОПЕДИЧЕСКИХ КОНСТРУКЦИЙ, ИЗГОТОВЛЕННЫХ С ПОМОЩЬЮ ЦИФРОВЫХ И ТРАДИЦИОННЫХ ТЕХНОЛОГИЙ
}

\section{RESULTS OF CLINICAL EVALUATION OF THE QUALITY OF TEMPORARY ORTHOPEDIC STRUCTURES MADE USING DIGITAL AND TRADITIONAL TECHNOLOGIES}

\section{J. Vokulova \\ E. Zhulev}

Summary. Aim - conduct a clinical assessment of the quality of temporary orthopedic structures made using digital and traditional technologies. Patients were divided into three groups according to the method of manufacturing temporary fixed prostheses - from Protemp 4 composite material using a silicone key, using the KaVo ARCTIC CAD/ CAM system from Vita CAD-Temp multicolor polymethylmethacrylate, and using the Asiga Max UV 3D printer from the biologically compatible NextDent C\&B MFH material. Clinical evaluation of prosthetic devices was performed based on the criteria of the modified USPHS test. The exact Fischer test was used for statistical analysis of the results obtained. Statistically significant differences $(p<0.00417)$ between traditional and digital methods of manufacturing temporary orthopedic structures during clinical evaluation based on a modified USPHS test were found for the following criteria: color matching, surface quality, the need to correct inter-occlusal relationships, and the quality of interproximal contacts. The results obtained allow us to conclude that the technologies of intraoral laser scanning, computer modeling and automated production using a milling and grinding machine and a 3D printer make it possible to obtain temporary orthopedic structures with dense interdental contact points and pre-verified inter-occlusal relationships using a virtual articulator, which is quite difficult to obtain using the traditional method of manufacturing medical prostheses using a silicone key. According to the "Color matching" criterion, statistical differences were found when comparing the subtractive and clinical methods of manufacturing artificial crowns $(p<0.00139)$, but no statistical differences were found when comparing the additive method with the clinical and subtractive methods.

Keywords: digital technologies in dentistry, digital impressions, CAD/CAM, intraoral scanner, 3D printing, temporary crown.
Вокулова Юлия Андреевна

К.м.н., врач стоматолог - ортопед, ФГКУ «Поликлиника № 2 Федеральной таможенной службы России», Нижний Новгород vokulova@rambler.ru

Жулев Евгений Николаевич

Заслуженный работник высшей школы РФ, д.м.н., профессор, ФГБОУ ВО «Приволжский исследовательский медииинский университет» Минздрава России, Нижний Новгород

hrustalev54@mail.ru

Аннотация. Цель - провести клиническую оценку качества временных ортопедических конструкций, изготовленных с помощью цифровых и традиционных технологий. Пациенты были распределены на три группы в соответствии с методом изготовления временных несъемных протезов из композитного материала Protemp 4 с применением силиконового ключа, с помощью CAD/CAM системы KaVo ARCTICA из полиметилметакрилата VITA CAD-Temp multicolor и с помощью 3D принтера Asiga Max UV из биологически совместимого материала NextDent C\&B MFH. Клиническая оценка провизорных протезов проводилась на основе критериев модифицированного USPHS-теста. Для статистического анализа полученных результатов применяли точный тест Фишера. Статистически значимые отличия $(p<0,00417)$ между традиционным и цифровыми методами изготовления временных ортопедических конструкций при клинической оценке на основе модифицированного USPHS-теста были выявлены для следующих критериев: цветовое соответствие, качество поверхности, необходимость коррекции межокклюзионных взаимоотношений, качество интерпроксимальных контактов. Полученные результаты, позволяют сделать вывод о том, что технологии внутриротового лазерного сканирования, компьютерного моделирования и автоматизированного производства с помощью фрезерно-шлифовального станка и 3D принтера, позволяют получить временные ортопедические конструкции с плотными межзубными контактными пунктами и заранее выверенными с помощью виртуального артикулятора межокклюзионными взаимоотношениями, что достаточно трудно получить, применяя традиционный метод изготовления провизорных протезов при помощи силиконового ключа. По критерию «Цветовое соответствие» были выявлены статистические различия при сравнении субтрактивного и клинического методов изготовления провизорных искусственных коронок ( $><0,00139)$, но не были выявлены статистические различия при сравнении аддитивного метода с клиническим и субтрактивным методами.

Ключевые слова: цифровые технологии в стоматологии, цифровые оттиски, CAD/CAM, внутриротовой сканер, 3D печать, провизорные искусственные коронки. 


\section{Ввемение}

$\Pi$ ри протезировании несъемными ортопедическими конструкциями обязательным является изготовление временных протезов $[6,8]$. На сегодняшний день существуют цифровые и традиционные методы изготовления провизорных конструкций. В клинических условиях врач может изготовить временные протезы из самотвердеющего композиционного материала, применяя методику силиконового ключа, или лабораторным способом из акриловых пластмасс [5]. Цифровые методы создания провизорных протезов основаны на получении виртуальных изображений зубных рядов пациентов с помощью внутриротовых [1], либо лабораторных сканеров, компьютерном моделировании и автоматизированном производстве с помощью субтрактивного [7] либо аддитивного методов $[4,9]$. Предыдущие экспериментальные исследования были посвящены изучению размерной точности [2] и качеству внутреннего прилегания временных коронок [1], полученных с помощью цифровых технологий. На данный момент имеется мало данных о сравнительной клинической оценке временных протезов, изготовленных с помощью 3D принтеров, фрезерно-шлифовальных станков и традиционных технологий, что явилось предметом проведения настоящего исследования.

\section{Це^ь}

Провести клиническую оценку качества временных ортопедических конструкций, изготовленных с помощью цифровых и традиционных технологий.

\section{Материалы и методы исследования}

В клиническом исследовании участвовали 46 пациента (25 мужчин и 21 женщина) в возрасте от 33 до 68 лет. Пациентам проводилось ортопедическое лечение цельнокерамическими и металлокерамическими несъемными конструкциями.

Критерии включения пациента для участия в исследовании: письменное согласия, необходимость протезирования дефекта твердых тканей зубов и/или частичной потери зубов несъемными протезами. Критерии исключения: возраст моложе 18 лет, периодонтит, бруксизм, беременность и лактация, декомпенсированная стадия хронических заболеваний.

Пациенты были распределены на три группы. Первую группу составили 18 пациентов (8 мужчин и 10 женщин), ортопедическое лечение которым проводилось с применением временных несъемных протезов, изготовленных клиническим методом по технологии силиконового ключа из самотвердеющего бисакрилатного композитного материала автоматического замешивания Protemp 4 (3M Espe). Всего в данной группе были получены 41 провизорных протезов.

Вторую группу составили 17 пациентов (11 мужчин и 6 женщин), ортопедическое лечение которым проводилось с применением временных ортопедических конструкций, изготовленных методом фрезерования. Цифровые изображения зубных рядов были получены с помощью внутриротового лазерного сканера iTero Cadent (США). Затем в программном обеспечение DentalCAD2.2 Valletta проводили моделирование временных искусственных коронок. Далее из полиметилметакрилата VITA CAD-Temp multicolor в фрезерно-шлифовальном станке KaVo ARCTICA Engine были изготовлены 42 пластмассовые искусственные коронки.

Третью группу составили 11 пациентов (6 мужчин и 5 женщин), ортопедическое лечение которым проводилось с применением временных ортопедических конструкций, изготовленных методом быстрого прототипирования. Цифровые изображения зубных рядов были получены с помощью внутриротового лазерного сканера iTero Cadent (США). Затем в программном обеспечение DentalCAD2.2 Valletta проводили моделирование временных протезов. Далее с помощью 3D принтера Asiga Max UV были изготовлены временные искусственные коронки из биологически совместимого микронаполненного гибридного материала NextDent C\&B MFH. Всего у пациентов данной группы были изготовлены 42 временных искусственных коронки. Распределение пациентов по полу и методу изготовления провизорных коронок представлено в таблице 1.

Фиксация временных ортопедических конструкций пациентам всех групп осуществлялась цементом Relyx Temp NE (3M Espe). Время пользования провизорных протезов составляло 30 дней.

Клиническая оценка провизорных протезов проводилась на основе критериев модифицированного USPHS-теста [10-12]. Методика заключается в оценке определенных клинических параметров и проведении клинических тестов. Оценку состояния маргинальной десны мы проводили с помощью определения ассоциированного пародонтального индекса [3]. Исследование проводится с помощью стоматологического смотрового набора без использования специальных реактивов и аппаратуры. У каждого пациента изучали состояние пародонта у 10 зубов верхней и нижней челюсти, в том числе покрытых провизорными протезами, учитывая воспаление десны и кровоточивость при зондировании, глубину пародонтального кармана, подвижность зубов, рецессию десны (табл. 2). 
Таблица 1. Распределение пациентов по полу и методу изготовления провизорных коронок

\begin{tabular}{|l|l|l|l|} 
Метод изготовления провизорных коронок & Количество протезов & Пол & Жен. \\
\cline { 3 - 4 } & & Муж. & 10 \\
\hline Клинический метод по силиконовому ключу & 41 & 8 & 6 \\
\hline Субтрактивный метод & 42 & 11 & 5 \\
\hline
\end{tabular}

Таблица 2. Критерии оценки ассоциированного пародонтального индекса (Жулев Е.Н., Архангельская Е. А., 2020)

\begin{tabular}{|c|c|}
\hline Параметр & Критерии оценки \\
\hline \multirow{5}{*}{ А - воспаление десны } & 0 - воспаление отсутствует \\
\hline & 1 - воспаление десневого сосочка \\
\hline & 2 - воспаление десневого сосочка с частью маргинальной десны \\
\hline & 3 - воспаление всей маргинальной десны, включая десневой сосочек \\
\hline & 4 - воспаление альвеолярной десны \\
\hline \multirow{5}{*}{$\begin{array}{l}\text { Б - кровоточивость при зондировании } \\
\text { десневой борозды }\end{array}$} & 0 - отсутствует \\
\hline & 1 - кровоточивость десневого сосочка \\
\hline & 2 - тонкая кровяная линия у края десны \\
\hline & 3 - обильно заполненная кровью десневая борозда \\
\hline & 4 - профузное кровотечение \\
\hline \multirow{4}{*}{ В - пародонтальный карман } & 0 - глубина до 2 мм \\
\hline & 1 - глубина 3 мм \\
\hline & 2 - глубина 4 мм \\
\hline & 3 - глубина более 4 мм \\
\hline \multirow{5}{*}{ Г- подвижность зубов } & 0 - отсутствует \\
\hline & $\begin{array}{l}1 \text { - подвижность в пределах } 1 \text { мм в вестибуло-оральном направлении, не ощущаемая } \\
\text { больным; }\end{array}$ \\
\hline & 3 - подвижность 1-2 мм, ощущаемая больным \\
\hline & 5 - подвижность 2-3 мм, ощущаемая больным \\
\hline & 7 - подвижность более 3 мм, сопровождающаяся болезненными ощущениями. \\
\hline \multirow{5}{*}{$\begin{array}{l}\text { Д - рецессия десны (расстояние } \\
\text { от края десны до эмалево-цементной } \\
\text { границы) }\end{array}$} & 0 - отсутствие рецессии \\
\hline & 1 - рецессия в пределах 1-2 мм в области межзубных сосочков \\
\hline & 2 - равномерная рецессия десны в пределах 1-2 мм от эмалево-цементной границы \\
\hline & 3 - рецессия более 2 мм в средней части десны \\
\hline & 4 - рецессия более 3 мм по всему периметру корня зуба \\
\hline
\end{tabular}

Расчет проводили по формуле: Сумма баллов у каждого зуба/10 где 10 - число обследованных зубов.

Оценка результатов: 0,1-6,0 баллов - легкая степень тяжести заболевания пародонта; 6,1-10,0 баллов средняя степень тяжести заболевания пародонта; 10,121,0 баллов - тяжелая степень тяжести заболевания пародонта. Ассоциированный пародонтальный индекс рассчитывали в день фиксации провизорного протеза и через 30 дней.

Качество интерпроксимальных контактов временных искусственных коронок проверялось путем опроса пациентов по поводу попадания пищи между изготовленным провизорным протезом и соседними зубами. Цвет прови- зорных искусственных коронок определяли в соответствии с шкалой Vita Classical A1-D4 (VITA Zahnfabrik, Германия).

Оценка результатов проводилась через 1 месяц после фиксации временных протезов. Для статистического анализа полученных результатов применяли точный тест Фишера. В данном исследовании при первичном сравнении трех групп нулевая гипотеза отвергается на уровне статистической значимости $p<0,00417$. При расчете критического уровня значимости была введена поправка Бонферрони для учета множественных сравнений: 0,00417=0,05 / 12, где 0,05 - общепринятое значение критического уровня значимости для одинарного сравнения в медико-биологических исследованиях, а 12 - число сравнений. 
Таблица 3. Результаты клинической оценки качества временных ортопедических конструкций, изготовленных с помощью цифровых и традиционных технологий

\begin{tabular}{|c|c|c|c|c|c|c|c|}
\hline \multirow[t]{2}{*}{ №№ } & \multirow{2}{*}{\multicolumn{3}{|c|}{ Критерии модифицированного USPHS-теста }} & \multicolumn{3}{|c|}{$\begin{array}{l}\text { Результаты } \\
\text { клинической оценки временных } \\
\text { конструкций, изготовленных } \\
\text { различными методами }\end{array}$} & \multirow[t]{2}{*}{$\mathbf{p}$} \\
\hline & & & & $\begin{array}{l}\text { По сили- } \\
\text { коновому } \\
\text { ключу }\end{array}$ & $\begin{array}{l}\text { Субтрак- } \\
\text { тивный } \\
\text { метод }\end{array}$ & $\begin{array}{l}\text { Адди- } \\
\text { тивный } \\
\text { метод }\end{array}$ & \\
\hline \multirow[t]{2}{*}{1} & \multirow[t]{2}{*}{ Аллергические реакции } & A & $\begin{array}{l}\text { Отсутствие аллергических } \\
\text { реакций }\end{array}$ & 41 & 42 & 42 & \multirow[t]{2}{*}{1} \\
\hline & & B & Наличие аллергических реакций & 0 & 0 & 0 & \\
\hline \multirow{3}{*}{2} & \multirow{3}{*}{$\begin{array}{l}\text { Краевая адаптация } \\
\text { (прилегание протеза } \\
\text { в пришеечной части } \\
\text { зуба оценивается } \\
\text { с помощью зонда) }\end{array}$} & A & $\begin{array}{l}\text { Плотное прилегание, зонд } \\
\text { не застревает }\end{array}$ & 31 & 38 & 37 & \multirow{3}{*}{0,131} \\
\hline & & B & $\begin{array}{l}\text { Край коронки ощущается } \\
\text { зондом, клинически приемлемо }\end{array}$ & 10 & 4 & 5 & \\
\hline & & C & $\begin{array}{l}\text { Ощутимый и визуально } \\
\text { заметный зазор, клинически } \\
\text { неприемлемо }\end{array}$ & & 0 & 0 & \\
\hline \multirow{4}{*}{3} & \multirow{4}{*}{$\begin{array}{l}\text { Состояние десневого } \\
\text { края } \\
\text { в день фиксации } \\
\text { протеза }\end{array}$} & A & Нет заболеваний пародонта & 16 & 7 & 10 & \multirow{4}{*}{0,0683} \\
\hline & & B & Легкая степень тяжести & 25 & 35 & 32 & \\
\hline & & C & Средняя степень тяжести & 0 & 0 & 0 & \\
\hline & & D & Тяжелая степень тяжести & 0 & 0 & 0 & \\
\hline \multirow{4}{*}{4} & \multirow{4}{*}{$\begin{array}{l}\text { Состояние десневого } \\
\text { края } \\
\text { через } 30 \text { дней }\end{array}$} & A & Нет заболеваний пародонта & 15 & 9 & 2 & \multirow{4}{*}{0,326} \\
\hline & & B & Легкая степень тяжести & 26 & 33 & 30 & \\
\hline & & C & Средняя степень тяжести & 0 & 0 & 0 & \\
\hline & & D & Тяжелая степень тяжести & 0 & 0 & 0 & \\
\hline \multirow{2}{*}{5} & \multirow{2}{*}{ Цветовое соответствие } & A & $\begin{array}{l}\text { Цвет конструкции } \\
\text { не отличается от исходного }\end{array}$ & 32 & 42 & 38 & \multirow{2}{*}{0,00138} \\
\hline & & B & $\begin{array}{l}\text { Цвет конструкции } \\
\text { отличается от исходного }\end{array}$ & 9 & 0 & 4 & \\
\hline \multirow{3}{*}{6} & \multirow{3}{*}{$\begin{array}{l}\text { Качество } \\
\text { поверхности* } \\
\text { (визуально после } \\
\text { предварительного } \\
\text { высушивания } \\
\text { поверхности воздухом) }\end{array}$} & A & $\begin{array}{l}\text { Поверхность гладкая, блестящая, } \\
\text { схожа с эмалью }\end{array}$ & 25 & 42 & 39 & \multirow{3}{*}{0,000000348} \\
\hline & & B & $\begin{array}{l}\text { Поверхность слегка } \\
\text { матовая, не блестит, имеет } \\
\text { шероховатости, устраняемые } \\
\text { полировкой }\end{array}$ & 16 & 0 & 3 & \\
\hline & & C & $\begin{array}{l}\text { Неприемлемая шероховатость } \\
\text { поверхности }\end{array}$ & 0 & 0 & 0 & \\
\hline \multirow[b]{2}{*}{7} & \multirow[b]{2}{*}{$\begin{array}{l}\text { Наличие сколов, } \\
\text { трещин, дефектов } \\
\text { поверхности } \\
\text { (визуально } \\
\text { и инструментально } \\
\text { зондом после } \\
\text { предварительного } \\
\text { высушивания воздухом) }\end{array}$} & A & Отсутствие & 34 & 37 & 36 & \multirow[b]{2}{*}{0,774} \\
\hline & & B & Наличие & 7 & 5 & 6 & \\
\hline
\end{tabular}


Таблица 3 (продолжение). Результаты клинической оценки качества временных ортопедических конструкций, изготовленных с помощью цифровых и традиционных технологий

\begin{tabular}{|c|c|c|c|c|c|c|c|}
\hline \multirow[t]{2}{*}{ №№ } & \multirow{2}{*}{\multicolumn{3}{|c|}{ Критерии модифицированного USPHS-теста }} & \multicolumn{3}{|c|}{$\begin{array}{l}\text { Результаты } \\
\text { клинической оценки временных } \\
\text { конструкций, изготовленных } \\
\text { различными методами } \\
\end{array}$} & \multirow[t]{2}{*}{ p } \\
\hline & & & & $\begin{array}{l}\text { По сили- } \\
\text { коновому } \\
\text { ключу }\end{array}$ & $\begin{array}{l}\text { Субтрак- } \\
\text { тивный } \\
\text { метод } \\
\end{array}$ & \begin{tabular}{|l} 
Адди- \\
тивный \\
метод \\
\end{tabular} & \\
\hline \multirow{2}{*}{8} & \multirow{2}{*}{ Ретенция протеза } & A & $\begin{array}{l}\text { Отсутствие случаев } \\
\text { расцементировки }\end{array}$ & 36 & 38 & 37 & \multirow{2}{*}{0,94} \\
\hline & & B & $\begin{array}{l}\text { Расцементировка или } \\
\text { подвижность протеза }\end{array}$ & 5 & 4 & 5 & \\
\hline \multirow[b]{2}{*}{9} & \multirow{2}{*}{$\begin{array}{l}\text { Необходимость } \\
\text { коррекции } \\
\text { межокклюзионных } \\
\text { взаимоотношений }^{*}\end{array}$} & A & Отсутствие & 8 & 32 & 33 & \multirow[b]{2}{*}{0,00000000375} \\
\hline & & B & Наличие & 33 & 10 & 9 & \\
\hline \multirow{2}{*}{10} & \multirow{2}{*}{ Перелом протеза } & A & Отсутствие & 36 & 40 & 38 & \multirow{2}{*}{0,458} \\
\hline & & B & Наличие & 5 & 2 & 4 & \\
\hline \multirow{3}{*}{11} & \multirow{3}{*}{$\begin{array}{l}\text { Качество } \\
\text { интерпроксимальных } \\
\text { контактов }^{*}\end{array}$} & A & Плотный контакт & 25 & 39 & 39 & \multirow{3}{*}{0,000156} \\
\hline & & B & $\begin{array}{l}\text { Отсутствие контакта, клинически } \\
\text { неприемлемо }\end{array}$ & 0 & 0 & 0 & \\
\hline & & C & Слабый контакт & 16 & 3 & 3 & \\
\hline \multirow{3}{*}{12} & \multirow{3}{*}{$\begin{array}{l}\text { Субъективные } \\
\text { ощущения пациента } \\
\text { (опрос) }\end{array}$} & A & $\begin{array}{l}\text { Отсутствие дискомфортных } \\
\text { явлений, быстрое привыкание }\end{array}$ & 35 & 38 & 39 & \multirow{3}{*}{0,626} \\
\hline & & B & $\begin{array}{l}\text { Наличие легкого дискомфорта, } \\
\text { ощущения непривычности }\end{array}$ & 5 & 4 & 3 & \\
\hline & & C & Непреодолимый дискомфорт & 1 & 0 & 0 & \\
\hline
\end{tabular}

Примечание «*» — различия статистически значимы по точному тесту Фишера на уровне $\mathrm{p}<0,00417$.

Таблица 4. Результаты попарного сравнения методов изготовления временных искусственных коронок по критерию «Цветовое соответствие»

\begin{tabular}{|l|l|}
\hline Попарное сравнение групп & $p$ \\
\hline Клинический метод — Субтрактивный метод & $0,00107^{*}$ \\
\hline Клинический метод — Аддитивный метод & 0,141 \\
\hline Субтрактивный метод — Аддитивный метод & 0,116 \\
\hline
\end{tabular}

Примечание «*» — различия статистически значимы по точному тесту Фишера на уровне $\mathrm{p}<0,00139$.

В случае обнаружения статистически значимых различий между тремя группами, далее проводилось попарное сравнение групп. При этом вводилась дополнительная поправка Бонферрони и критический уровень значимости рассчитывался как 0,00139 =0,00417 / 3, где 3- число попарных сравнений для трех групп.

\section{Результаты и обсужление}

Результаты клинической оценки качества временных ортопедических конструкций, изготовленных с помо- щью цифровых и традиционных технологий, представлены в таблице 3.

В ходе проведения исследования не было выявлено случаев возникновения аллергических реакций. Плотное краевое прилегание временных несъемных протезов, изготовленных клиническим методом по силиконовому ключу, было выявлено в 75,6\% случаев, изготовленных в CAD/CAM системе KaVo ARCTICA в 90,5\% и с помощью 3D принтера Asiga Max UV в 88,1\%. Значения ассоциированного пародонтального индекса 
Таблица 5. Результаты попарного сравнения методов изготовления временных искусственных коронок по критерию «Качество поверхности»

\begin{tabular}{l|l} 
Попарное сравнение групп & $p$ \\
\hline Клинический метод — Субтрактивный метод & $0,00000199^{*}$ \\
\hline Клинический метод - Аддитивный метод & $0,000605^{*}$ \\
\hline Субтрактивный метод - Аддитивный метод & 0,241
\end{tabular}

Примечание «*» - различия статистически значимы по точному тесту Фишера на уровне $\mathrm{p}<0,00139$.

Таблица 6. Результаты попарного сравнения методов изготовления временных искусственных коронок по критерию «Необходимость коррекции межокклюзионных взаимоотношений»

\begin{tabular}{|l|l|}
\hline Попарное сравнение групп & $\mathbf{p}$ \\
\hline Клинический метод — Субтрактивный метод & $0,000000244^{*}$ \\
\hline Клинический метод - Аддитивный метод & $0,0000000682^{*}$ \\
\hline Субтрактивный метод — Аддитивный метод & 1 \\
\hline
\end{tabular}

Примечание «*» - различия статистически значимы по точному тесту Фишера на уровне $\mathrm{p}<0,00139$.

Таблица 7. Результаты попарного сравнения методов изготовления временных искусственных коронок по критерию «Качество интерпроксимальных контактов»

\begin{tabular}{|l|l|}
\hline Попарное сравнение групп & p \\
\hline Клинический метод - Субтрактивный метод & $0,000605^{*}$ \\
\hline Клинический метод - Аддитивный метод & $0,000605^{*}$ \\
\hline Субтрактивный метод — Аддитивный метод & 1 \\
\hline
\end{tabular}

Примечание «*» - различия статистически значимы по точному тесту Фишера на уровне $\mathrm{p}<0,00139$.

во всех группах в большинстве случаев соответствовало легкой степени тяжести заболевания пародонта. Цветовая стабильность провизорных конструкций отличалась в зависимости от метода их изготовления. В таблице 4 приведены результаты попарного сравнения методов изготовления временных искусственных коронок по критерию «Цветовое соответствие».

Провизорные протезы, изготовленные цифровыми методами, имели лучшее качество поверхности, по сравнению с временными конструкциями, полученными традиционным методом. В таблице 5 приведены результаты попарного сравнения методов изготовления временных искусственных коронок по критерию «Качество поверхности».

Наличие сколов, трещин и переломов временных протезов во всех группах составило менее 18\%. Отсутствие случаев расцементировки провизорных конструкций во всех группах составило более $85 \%$. Необходимость коррекции межокклюзионных взаимоотношений временных несъемных протезов встречалась реже при применении цифровых методов. В таблице 6 приведены результаты попарного сравнения методов изготовления временных искусственных коронок по критерию «Необходимость коррекции межокклюзионных взаимоотношений».
Временные протезы, изготовленные цифровыми методами, имели лучшее качество интерпроксимальных контактов, по сравнению с временными конструкциями, полученными традиционным методом. В таблице 7 приведены результаты попарного сравнения методов изготовления временных искусственных коронок по критерию «Качество интерпроксимальных контактов».

Наличие легкого дискомфорта, ощущения непривычности после фиксации временных протезов во всех группах составило менее $13 \%$.

Полученные результаты, позволяют сделать вывод о том, что технологии внутриротового лазерного сканирования, компьютерного моделирования и автоматизированного производства с помощью фрезерно-шлифовального станка и 3D принтера, позволяют получить временные ортопедические конструкции с плотными межзубными контактными пунктами и заранее выверенными с помощью виртуального артикулятора межокклюзионными взаимоотношениями, что достаточно трудно получить, применяя традиционный метод изготовления провизорных протезов при помощи силиконового ключа. Полученные нами результаты подтвердили данные Waldecker M., et al. [13], которые пришли к выводу о том, 
что несъемные протезы, изготовленные с помощью 3D принтера, по цифровым изображениям зубных рядов, полученным внутриротовым сканером, нуждались в незначительной окклюзионной коррекции.

По критерию «Цветовое соответствие» были выявлены статистические различия при сравнении субтрактивного и клинического методов изготовления временных искусственных коронок $(p<0,00139)$, но не были выявлены статистические различия при сравнении аддитивного метода с клиническим и субтрактивным методами.

\section{Зак^ючение}

Статистически значимые отличия ( $p<0,00417)$ между традиционным и цифровыми методами изготовления временных ортопедических конструкций при клинической оценке на основе модифицированного USPHS-теста были выявлены для следующих критериев:

1. цветовое соответствие;

2. качество поверхности;

3. необходимость коррекции межокклюзионных взаимоотношений;

4. качество интерпроксимальных контактов.

\section{ЛИТЕРАТУРА}

1. Жулев Е.Н., Вокулова Ю. А. Изучение размерной точности внутреннего прилегания искусственных коронок к культе опорного зуба и цифровых оттисков В эксперименте. Кубанский научный медицинский вестник.— 2016; 6 (161): 58-62. Dol.org/10.25207/1608-6228-2016-6-58-62.

2. Жулев Е.Н., Вокулова, Ю. А. Изучение размерной точности искусственных коронок, изготовленных спомощью CAD/CAM системы и 3D принтера. Znanstvena misel. - 2020;2 (40): 20-25.

3. Жулев Е.Н., Архангельская Е. А. Способ оценки состояния тканей пародонта. — Патент RU на изобретение № 2722445, действ. с 01.06.2020.

4. Карякин Н.Н., Горбатов Р. 0. 3D-печать в медицине.- М.: ГЭОТАР-Медиа: 2019. — С. 194-221.

5. Лебеденко И.Ю., Арутюнов С. Д., Ряховский. Ортопедическая стоматология: национальное руководство. — М.: ГЭОТАР-Медиа, 2016. - С. 158.

6. Розенштиль С.Ф., Лэнд М. Р., Фуджимото Ю. Ортопедическое лечение несъемными протезами. Пер. сангл.; под общ. ред. проф. Лебеденко И. Ю.—- М.: Рид Элсивер, - 2010.- С. 395-429.

7. Ряховский, А. Н. Цифровая стоматология.— М.: 000 «Авантис», — 2010.—C. 106-112.

8. Смит Б., Хоу Л. Коронки и мостовидные протезы в ортопедической стоматологии. Пер. с англ.; под общ. ред. Е. Ю. Новикова.—- М.: МЕДпресс-информ,2010,-C. 140-141.

9. Шустова В.А., Шустов М. А. Применение 3D-технологий в ортопедической стоматологии. — СПб: СпецЛит, - 2016. - C. 8-44.

10. Barnes D.M., Blank L.W., Clive Gingell J., Gilner P. P. A clinical evaluation of a resin-modified glass ionomer restorative material.— J. Amer. Dent. Assoc.—1995; 126: 1245-1253. D0l: 10.14219/jada.archive.1995.0359.

11. Haselton D.R., Diaz-Arnold A.M., Hillis S. L. Clinical assessment of high-strength all-ceramic crowns. — Prosthet. Dent.—2000; 83(4): 396. D0I: 10.1016/S0022$3913(00)$ 70033-3.

12. Koch M.J., Garcia-Godoy F. The clinical performance of laboratory fabricated crowns placed on first permanent molars with developmental defects. - J. Amer. Dent. Assoc. — 2000; 131:1285-1290. D0l: 10.14219/jada.archive.2000.0382.

13. Waldecker M., Leckel M., Rammelsberg P., Bömicke W. Fully digital fabrication of an occlusal device using an intraoral scanner and 3D printing: A dental technique // The Journal of prosthetic dentistry. — 2019.—V. 121.—№ . 4. - P. 576-580. 